\title{
Study on Present Situation of Full-time Engineering Master in Hebei Province $^{*}$
}

\section{Qingqing Huo, \&Jinqiang Geng}

Shijiazhuang University of Economics, Shijiazhuang, 050031, China

Dongye Liu

Hebei University of Economics and Business, Shijiazhuang, 050061, China

\begin{abstract}
Through investigation, this paper analyzes the present situation of full-time engineering master in Hebei province, through the methods of document data, information collecting, questionnaire survey and qualitative analysis. This investigation contains three parts, which are enrollment, education goal and process of training. At last, suggestions are introduced to lay theoretical foundation for the training of full-time engineering master in Hebei Province. And in practice, this research is helpful for the training system to build its standards which accommodate the goal of training application oriented talents.
\end{abstract}

KEYWORD: Present Situation; Full-time Engineering Master; Hebei Province

\section{INTRODUCTION}

Since the enrollment of full-time engineering master, universities pay more attention to this job. To ensure the training quality and provide high level talents for the society, universities make relevant rules and regulations based on the documents of education ministry. But for most of the universities, the training of full-time engineering master is a new theme. It is different from the training of master of engineering science and non full-time engineering master. So, to ensure and improve the training quality of full-time engineering master is a challenge and opportunity for the universities.

\section{INVESTIGATION}

\subsection{Research Purpose}

To have a further understanding of the training situation of full-time engineering master in Hebei province, the research group did a research in June, 2014. The training situation and problems are analyzed through this research. This research could lay theoretical foundation for the training of fulltime engineering master in Hebei Province, and in practice, this research is helpful for the training system to build its standards which accommodate the goal of training application oriented talents.

\footnotetext{
* This paper is the education planning project of Education Department of Hebei Province in 2014, the project number is GH141094.
}

\subsection{Object of Study}

This research investigates the class of 2010、2011 and 2012 graduate students, who are from 8 universities of 20 fields.

\subsection{Research Contents}

The questionnaire contains three parts: enrollment, education goal and process of training.

(1) Enrollment is about enrollment motivation and attitude, the awareness of engineering master.

(2) Educational goal is about postgraduates' understanding of the present educational goal.

(3) Process of training is about curriculum, teaching methods and assessment, professional practice and thesis.

\subsection{Research Methods}

Methods used in this research are document data, information collecting, questionnaire survey and qualitative analysis. The number of questionnaire given out is 240 in all, recovery valid questionnaires is 223 , and the rate of recovery is $92.9 \%$, which meets the effective range of investigation.

\section{ANALYSIS OF INVESTIGATION DATA}

\subsection{Enrollment}

Enrollment motivation has great influence on attitude, devotion and quality of learning. For the students investigated, before their registrations, their 
understanding of full-time engineering master is insufficient. Students who have a general understanding of it take $76.8 \%$, who know nothing of it take $16.5 \%$, who know it very well only take $6.7 \%$. For application, postgraduates transferred from master of engineering science takes $52.1 \%$ (see Form 1), in which the reason for not choosing engineering master is knowing nothing about it takes $28.3 \%$.

Form 1 Distribution of Enrollment Motivation for Full-time Engineering Mater

\begin{tabular}{|c|c|c|c|}
\hline $\begin{array}{c}\text { Enrollment } \\
\text { Motivation }\end{array}$ & $\begin{array}{l}\text { First } \\
\text { Choice }\end{array}$ & $\begin{array}{c}\text { Transferred } \\
\text { from } \\
\text { Engineering } \\
\text { Master }\end{array}$ & $\begin{array}{c}\text { Transferred } \\
\text { from master of } \\
\text { engineering } \\
\text { science }\end{array}$ \\
\hline Proportions & $32.1 \%$ & $15.8 \%$ & $52.1 \%$ \\
\hline Total & \multicolumn{2}{|c|}{$47.9 \%$} & $52.1 \%$ \\
\hline
\end{tabular}

It could be concluded that, according to the analysis above, graduate students know a little about engineering master before their registration, and some knows nothing about it. Besides, being anxious for future and regarding engineering master inferior result in low enthusiasm in learning. For the graduate students who choose this type actively, the proportion of which is $47.9 \%$. And the proportion of reasons for choosing it, which are being admitted easily and short schooling duration, is $48.2 \%$. Enrollment reasons could have some influence on learning attitude and quality to some extent.

\subsection{Education Goal}

Full-time engineering master focuses on engineering application and its education goal emphasizes on training application oriented talents. Education goals of different universities in Hebei province are basically the same. However, compared with master of engineering science, graduates' knowledge about education goal of engineering master is insufficient. Graduates who know a little about its education goal account for $55.2 \%$, and those who know nothing about it account for $4.9 \%$. This shows that universities don't pay sufficient attention to this type of education. As for the matter of whether the education goal being accordance with the need of the society, $34 \%$ of the graduates give the no answer. This shows that there could be some problems in the process of training.

\subsection{Process of Training}

\subsubsection{Curriculum}

The curriculum arrangement of full-time engineering master should be reasonable and scientific. $66.7 \%$ of the graduate students think there are more theoretical courses than practical courses. As for the matter of whether the curriculum is in accordance with the vocational need, $68.1 \%$ of the graduate students give the no answer. When asked whether the curriculum is in accordance with education goal, $27.2 \%$ of the graduate students give the answer of "no", only $2.2 \%$ of the graduate students give the answer of "match very well".

Based on the investigation above, curriculum of full-time engineering master in Hebei province has the following problems:

Firstly, the special law of full-time engineering master, which is the close combination of scholarship and profession, is not followed. Theory learning and engineering practice should be balanced. But in practice, there exists the phenomenon that the curriculum of master of engineering science is copied by engineering master. Besides, theoretical courses surpass practical ones.

Secondly, the setting of the curriculum in different universities follows the same pattern and the content of curriculum is outdated. For the curriculum of full-time engineering master in Hebei province, it doesn't vary from university to university, from cooperative enterprise to cooperative enterprise and from area to area. It can't keep up with the development of technology.

\subsubsection{Teaching Method}

The teaching method should be the combination of different methods. Through the investigation on teaching method, the primary method is teacherbased teaching. The proportion of "Class discussion" is $65 \%$, "case analysis" is $49 \%$, "team working" is $61.9 \%$. As for the matter of whether the teacher combines the theoretical knowledge with practice in class, $26 \%$ of the graduate students choose the answer of "no". It could be concluded that the present teaching method is flexible, but for the teachers, the combination of theoretical knowledge with practice in class is insufficient.

\subsubsection{Tutors' Coaching}

Engineering master implements "Double Tutorial System". According to the investigation, this system, in Hebei province, has the following problems. Firstly, some tutor is lack of engineering experience, which results in the academic feature of teaching content in class. Secondly, the system of tutor cooptation is imperfect. After theoretical learning in university, graduate students go to enterprise to practice. But the enterprise tutors' task is not distinct. So there is no proper communication between the two tutors.

\subsubsection{Professional Practice in Enterprise}

Professional practice is an important method of improving graduate students' practical ability. Through investigation, professional practice has 
three problems. Firstly, the development of practice base is not perfect. At present, some practice is arranged by the department, some by the tutors and some by the graduate students themselves. This indicates that the development of practice base in Hebei province is in its infancy, which couldn't satisfy the practice demand of graduate students. Secondly, theory learning in university is disconnected with the practice out of the university. At present, theory learning is followed by practice in enterprise. To some extent, this has some influence on the effect of practice and the combination of theory and practice.

\subsubsection{Dissertation}

Dissertation is an important part of education and it is an important index of education quality. Dissertation of full-time engineering master should be different from that of master of engineering science. It should be sourced from application subject and have vocational background and application value[1]. Through this investigation, the dissertation of full-time master of engineering has the following problems.

Firstly, academic tendency exists in dissertation. $36.3 \%$ of the graduate students regards academic tendency existing in dissertation. There are many reasons for this tendency. Such as similar curriculum with master of engineering science, disconnection between theory and practice in class, lack of communication between tutors.

Secondly, evaluation index of different forms of dissertation are not regulated. In 2011, the National Education Commission of engineering master puts forward to 5 forms of dissertation which are product development, engineering design, application research, engineering/project management and investigation report[2]. However, at present, the form of dissertation is not diverse and there is no scientific and targeted evaluation index. As a result, for the review of dissertation, the standard of academic dissertation is followed to some extent.

\section{SUGGESTIONS}

Full-time engineering master in Hebei province is in a stable development. However, there is some work that needs to be improved. Problems about curriculum setting, teaching method, tutors' coaching, practice in enterprise and dissertation need to be solved. The following suggestions are introduced to improve the quality of education.

\subsection{Cooperation between university and enterprise should be strengthened}

Firstly, cooperation between university and enterprise signifies vocation orientation. Enterprise needs technology supplied by university. So the cooperation is helpful for the university to update teaching content according to the need of enterprise and improve the combination of scholarship with profession. This can improve the renewal of curriculum of full-time engineering master. Secondly, this measure could improve practice ability of graduate students. For this cooperation provides a way for students to practice in enterprise. Besides, university could choose better enterprise tutor who is likely to make adequate communication with intramural tutor, which is helpful for the students to put theory into practice. Thirdly, students' learning interest could be enhanced. Some students' learning interest abate for the reason that they are not very clear about this education type or they don't consider there is a promising future. Through practice, students could recognize their weakness and they will learn actively in the future to improve their quality. In short, cooperation between university and enterprise is in accordance with the specialty and law of full-time engineering master.

\subsection{Optimize tutor team and define tutor's responsibilities and powers}

Firstly, tutor team should be optimized. Except for employing expert in enterprise as tutor, teachers with engineering ability and background should be introduced. Besides, introduction of new teachers cannot satisfy university's need for teachers, training and management of teachers should be strengthened. Tutors should be trained on time with existing resources. Policy about practice in enterprise should be made to improve teacher's practice ability. Secondly, tutors' responsibilities and powers should be defined. Tutor is the first person who is responsible for students' education. In the aspects of graduates' learning, dissertation and thesis defense, tutors' responsibilities and powers should be defined and strengthened. And the responsibilities and powers should be listed as part of tutor's appraisal system. Besides, the selection of outstanding tutor could improve the level of tutor team.

\subsection{Relative policy should be regulated and management should be strengthened}

Firstly, policy about tutors' appointment, appraisement should be regulated. Tutors' coaching is the guarantee of education quality. But at present, for most of the universities, tutors' engineering background and ability is neglected in the selection of tutors. The policy of appointment and appraisement should be regulated to train high level and application oriented talents. Secondly, standard of dissertation writing should be regulated. This type of dissertation is practice and application oriented, which is different from academic dissertation. For 
example, the dissertation should be sourced from engineering practice; it should have engineering background and application value and so on. Besides, dissertation of different forms, evaluation index and ways of defense should be regulated.

\section{CONCLUSION}

Through investigation, it could be concluded that full-time engineering master is in a stale development in Hebei province. However, there are some problems that need to be solved. Reform should be implemented in different levels to satisfy the need of society. This is a long way that needs the efforts of universities, enterprises and government.

\section{REFERENCES}

[1] Opinions of Ministry of Education, Ministry of Human Resources and Social Security on further promotion of the training mode reform of professional degree. Education Research [2013]3.

[2] National Education Commission of engineering master Notice on trial implementation of requirement and evaluation index of different forms of thesis of engineering master National Education Commission (2011)11.

[3] Haiying Zhang et all. 2006. Investigation Report on Current Situation of Engineering Master in China. Research on Higher Engineering Education. 